\title{
Carbon Material with Fibonacci Parastichy Structure
}

\author{
Aohan Wang, Hiromasa Goto* \\ Division of Materials Science, Faculty of Pure and Applied Science, University of Tsukuba, Tsukuba, Japan \\ Email: *gotoh@ims.tsukuba.ac.jp
}

How to cite this paper: Wang, A. and Goto, H. (2017) Carbon Material with Fibonacci Parastichy Structure. Soft, 5, 1-8. https://doi.org/10.4236/soft.2017.51001

Received: December 14, 2016

Accepted: February 1, 2017

Published: February 4, 2017

Copyright (c) 2017 by authors and Scientific Research Publishing Inc. This work is licensed under the Creative Commons Attribution International License (CC BY 4.0).

http://creativecommons.org/licenses/by/4.0/ cc) (i) Open Access

\begin{abstract}
The curd of Romanesco broccoli was carbonized at $900^{\circ} \mathrm{C}$ under argon atmosphere in a gold furnace chamber. The carbonization afforded a carbon material with a fine logarithmic spiral on the surface, resembling the Fibonacci parastichy structure of the Romanesco broccoli flower bud. The carbonized "flower bud" structure was observed under scanning electron microscopy. Infrared absorption spectra and X-ray photoelectron spectroscopy measurements confirmed the chemical structure and component of the carbon material.
\end{abstract}

\section{Keywords}

Romanesco broccoli, Fibonacci Parastichy Structure, Three-Dimensional Carbon Material

\section{Introduction}

Carbon materials have had increasing attention due to their remarkable properties like conductivity and chemical stability. The morphology of the carbon materials at macro-scale provides for diversity of application, such as active carbon with a large amount of pores as a catalyst, carbon fiber for high-strength structural material.

Instead of bottom-up fabrication, carbonization of the organic compound containing large amounts of light elements, performed at high temperature in inert gas atmosphere, should afford a macro-scale carbon material with shape and fine structures preserved. Carbons with micro- or nano-sized structure resembling the starting material were obtained via the carbonization of natural plants [1] [2], DNA [3], and artificially synthesized organic compounds [4] [5]. This method is a facile and cost-effective way to apply carbons at industrial levels while conserving energy and preserving the environment. However, shape- 
conserving carbonization has been focused on the nano- or micro-scale in onedimensional or two-dimensional materials. From the aspects of application and scientific interest, it is necessary to examine properties of three-dimensional samples.

$3 \mathrm{D}$ printing technology accelerates the demand of 3D structural carbon-preserving method. This bottom-up method satisfies the demand to manufacture three-dimensional products with complex structure. Applications of 3D printing technology vary from functional materials [6], medical devices [7] [8] to the aerospace industry. Simultaneously, "ink" material for 3D printing technology expands the possibilities of material properties. As an example, Paul Gatenholm, et al., developed a novel bioink composed of a nano-fibrillated cellulose dispersion [9]. Since one of the most remarkable selling points of 3D printing is the convenience of unrestricted design [10], printing could provide excellent starting points for well-tailored carbon materials.

In this research, we chose the Fibonacci parastichy structure, a complex structure with aesthetic and scientific value, as an example for shape-retained carbonization. This structure is found in nature plant and animals, such as the curd of Romanesco broccoli [11], seed heads of sunflowers [12], and the shell of the chambered nautilus. Also, synthesized $\mathrm{Ag}-\mathrm{SiO}_{2}$ core-shell nano-particles with Fibonacci parastichy surface structures with self-similarity were reported recently [13].

In this report, Romanesco broccoli flower buds and stems were observed by microscope to study the Fibonacci parastichy structure. Then, the raw flower curd was carbonized at $900^{\circ} \mathrm{C}$ in the presence of argon. The flower bud consists of a large amount of cellulose and moisture. Carbonization created asynthesized carbon material with self-similar structure. Infrared absorption spectroscopy and $\mathrm{x}$-ray photoelectron spectroscopy (XPS) were utilized to determine structure.

\section{Experimental}

\subsection{Observation}

Figure 1(a) is an image of Romanesco broccoli curd before carbonization (Figure 1(a)). This structure is formed with many similar parts like a spiral tree consisting of much smaller ones. The underlying parts with no spiral components are observed under scanning electron microscopy (SEM) (Figure 1(b)). The small components of different sizes pack closely together. Figure 1(c) shows the cross section of the inside of the flower bud, where the middle part mostly consists of uniform cells (Figure 1(c)). It is worth noting that the Fibonacci parastichy structure was not only observed on the surface of the flower bud, but also in the fibro-vascular bundles adhered to the epidermis, as shown in Figure 1(d). In Figure 1(d), five parallel fibro-vascular bundles can be found, labelled numbers 1 to 5 , from left to right, respectively (Figure 1(d)). The distances between each adjacent fibro-vascular bundle were measured with a ruler, with results in Table 1. The calculated results do not follow the strict definition of the 


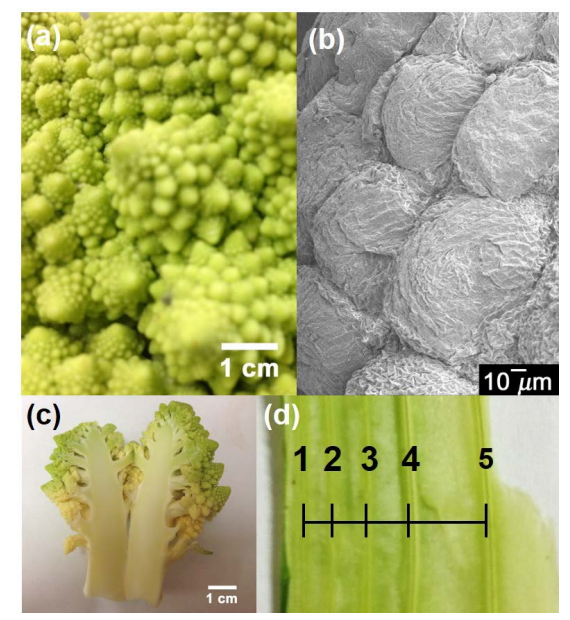

Figure 1. (a) Image of the Fibonacci parastichy structure of a Romanesco broccoli flower bud. (b) magnification ( $\times 370$ ) of a Romanesco broccoli flower bud observed under the scanning electron microscope; (c) Cross section image of a cluster of Romanesco broccoli curd; (d) Image of fibrovascular bundles adhering on the Romanesco broccoli stem epidermis.

Table 1. Calculated distance between adjacent fibrovascular bundles of Romanesco broccoli stem epidermis.

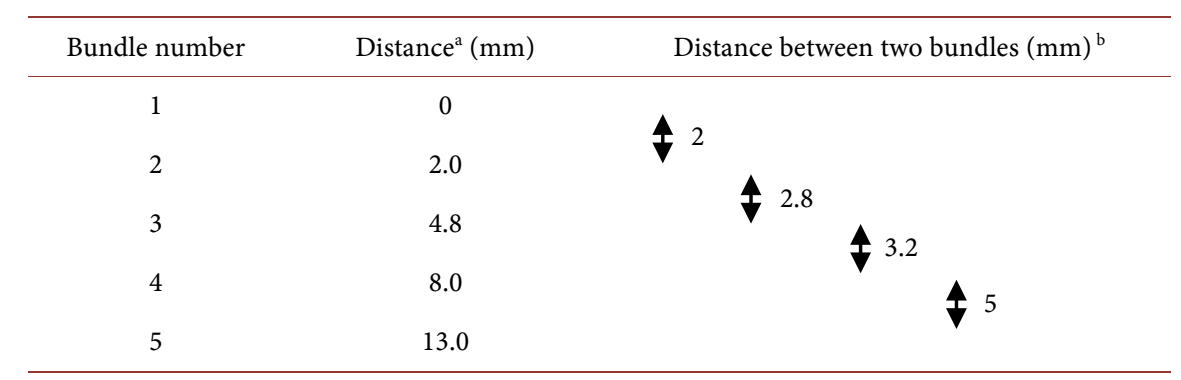

${ }^{\mathrm{a} D i s t a n c e}$ from bundle 1. ${ }^{\mathrm{b} I n c r e m e n t ~ l e n g t h . ~}$

Fibonacci sequence, $0,1,1,2,3,5,8, \ldots$, However, the difference might be related to the growth direction of the plants that effect the surface of the morphology of the flower bud.

\subsection{Carbonization}

A cluster of flower buds was carefully snipped off and washed with distilled water to remove the impurities on the surface. The sample was put in a quartz boat and set in a gold furnace chamber. Carbonization was performed by increasing the temperature from room temperature to $900^{\circ} \mathrm{C}$ in argon flow with flow rate of $200 \mathrm{~mL} / \mathrm{min}$ for $1 \mathrm{~h}$. The obtained carbon is shown in Figure 2 (Figures 2(a)(e)).

\section{Results and Discussion}

\subsection{Surface Observation}

Figure 2 shows the images of the carbonized Romanesco broccoli flower bud captured from different angles. The material turns to black color during carbo- 


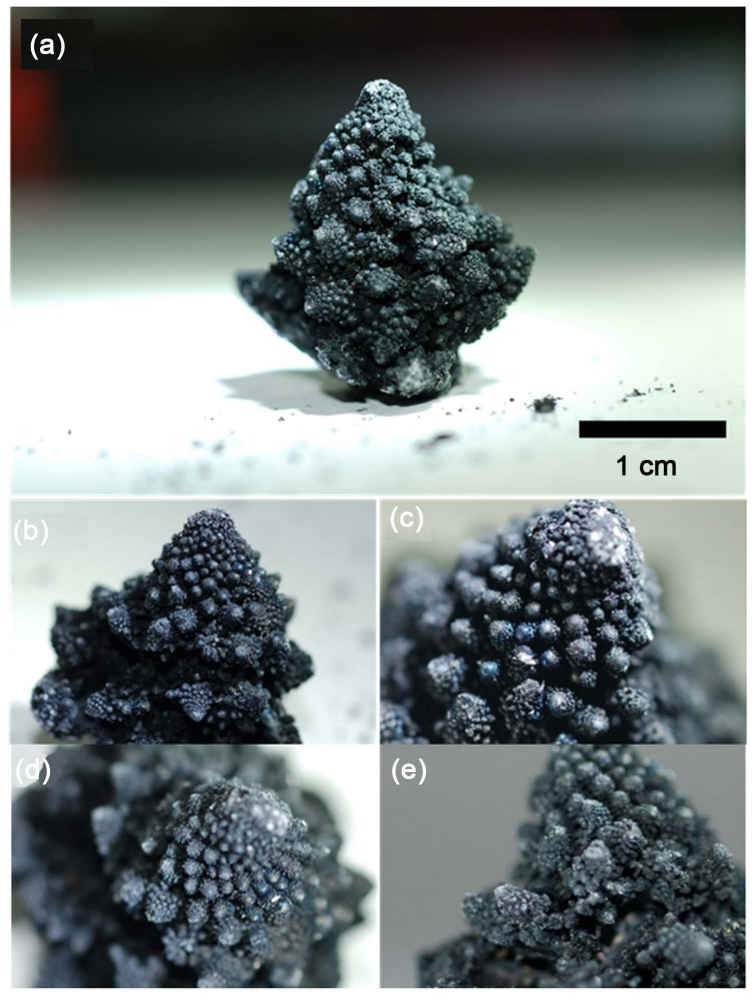

Figure 2. Image of the carbonized Romanesco broccoli flower bud taken for different angles.

nization. The shape of the whole cluster, and the Fibonacci parastichy structure on the surface, are well retained after carbonization (Figures 2(a)-(e)). The smaller clusters attached on the surface also show Fibonacci parastichy structure. The three-dimensional system was well preserved.

It is noteworthy that the Fibonacci parastichy structure was also found at micro-scale. Figure 3 shows the images observed under SEM (Figures 3(a)-(d)). The scale of the smallest three-dimensional Fibonacci parastichy structure on the surface of a Romanesco broccoli flower curd ranges around $50 \mu \mathrm{m}$ (Figure 3(b)). In Figure 3(c), small sphere-like particles were found on top of a cluster (Figure $3(\mathrm{c})$ ). The small pieces show volumetric shrinkage, with spiral lines comprised of cubic-like particles found on the apex of the curd (Figure 3(d)). Figure 4 is a SEM image of the shoot apical meristem in the developmental stage of the carbonized Romanesco broccoli. This image resembles the SEM graphof raw Romanesco very well (Figure 4) [11]. These results strongly suggest that a three-dimensional Fibonacci parastichy structure in microscale was achieved by carbonization.

\subsection{Infrared Absorption}

Figure 5 shows the IR absorption spectrum of the carbonized Romanesco broccoli. An intense absorption band at $1051 \mathrm{~cm}^{-1}$ is due to C-O-C stretching of cellulose backbones. An absorption band at $2940 \mathrm{~cm}^{-1}$ is due to stretching vibration of $\mathrm{CH}$ and $\mathrm{CH}_{2}$. The peak around $1600 \mathrm{~cm}^{-1}$ implies the formation of carbon. 


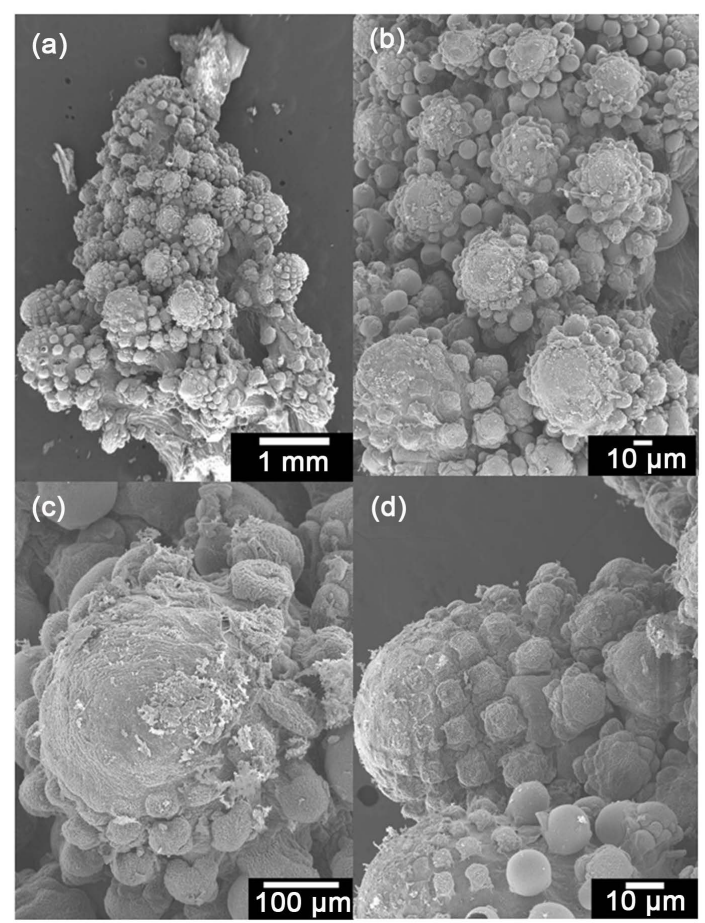

Figure 3. Scanning electron microscopy images of the carbonized Romanesco broccoli flower bud. (a) $\times 16$; (b) $\times 50$; (c) $\times 200$; (d) $\times 100$.

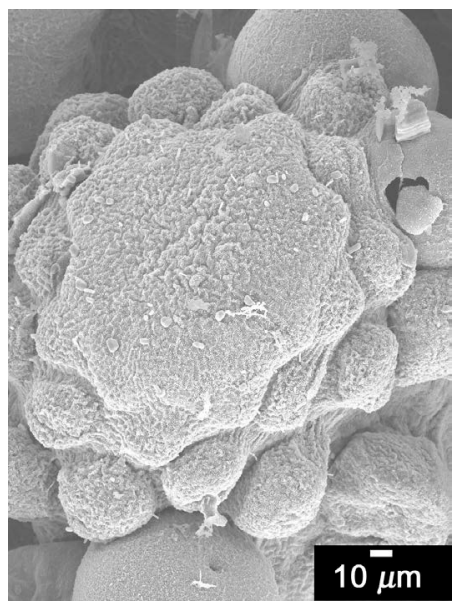

Figure 4. SEM image of a carbonized shoot apical meristem of Romanesco broccoli.

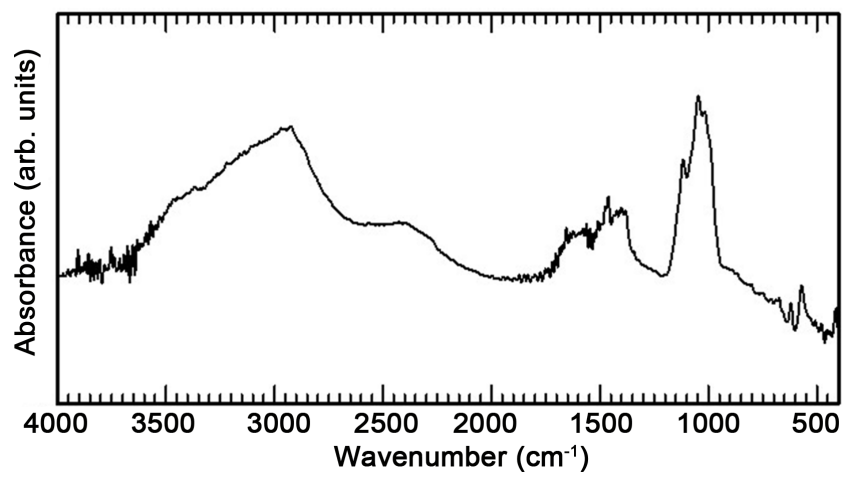

Figure 5. IR spectrum of the carbonized Romanesco broccoli. 


\subsection{X-Ray Photoelectron Spectroscopy}

XPS measurement was performed on the carbonized sample. Carbonization process leaves a material consisting mainly of carbon (285 eV) and oxygen (531 $\mathrm{eV}$ ) (Figure 6(a)). In addition, this measurement also identifies trace elements, such as potassium, calcium, phosphorus, aluminium, and iron (Figure 6(b)). These previously absorbed elements remain after carbonization.

\section{Conclusion}

Carbonization of a cluster of Romanesco broccoli was performed. The threedimensional Fibonacci parastichy structure in micro-scale was successfully achieved by carbonization. This is the first report about a carbon material showing Fibonacci parastichy structure. This research suggests that complex structure composed of cellulose can remain the 3D structure in macro scale. This study can open a new avenue to create tailored carbon materials.

\section{Techniques}

IR absorption spectra were obtained with a JASCO FT-IR 550 spectrometer. Carbonization was carried out with the Electric Gold Furnace instrument, MIT Lincoln-Lab., equipped with an Ishikawa temperature controller. SEM observations were carried out with JSM-7000F, NIMS, Japan. XPS analysis was performed with a JPS-9010TR (JEOL).

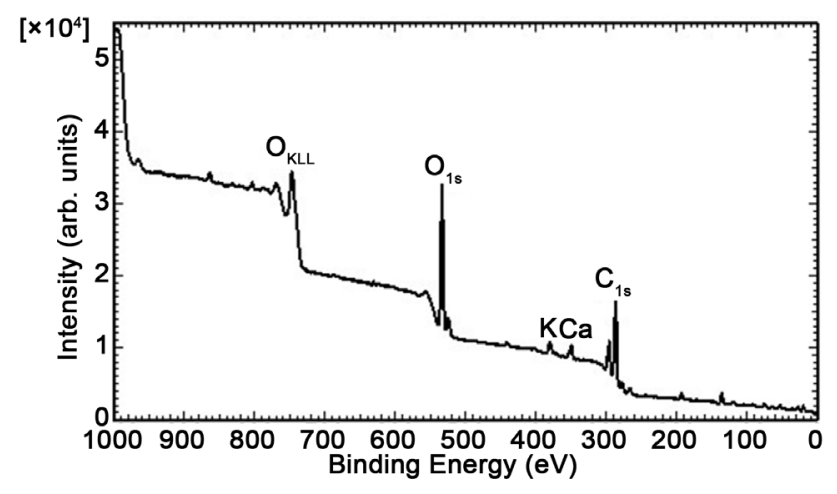

(a)

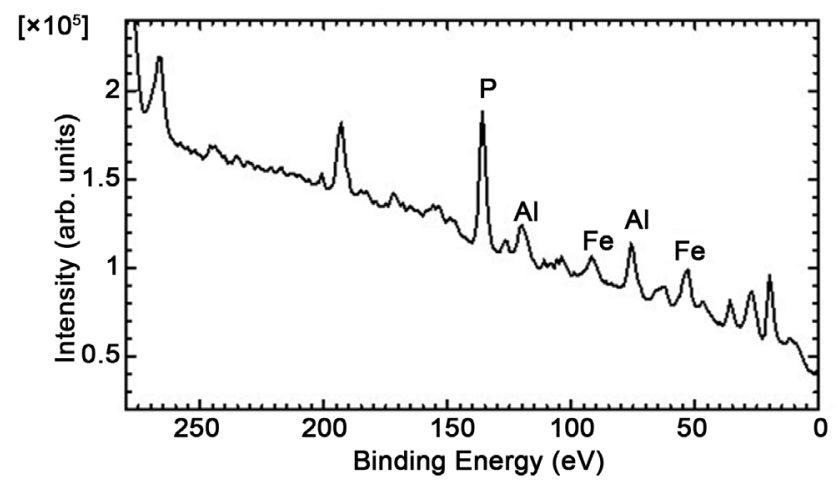

(b)

Figure 6. XPS spectrum of the carbonized Romanesco broccoli. 


\section{Acknowledgements}

We are thankful to Research Facility Center for Science and Technology, Open Facility Network Office for XPS measurement. This work was partially supported by NIMS microstructural characterization platform as a program of the "Nanotechnology Platform" of the Ministry of Education, Culture, Sports, Science and Technology (MEXT), Japan.

\section{References}

[1] Liang, Y., Wu, D. and Fu, R. (2013) Carbon Microfibers with Hierarchical Porous Structure from Electrospun Fiber-Like Natural Biopolymer. Scientific Report, 3, Article ID: 1119. https://doi.org/10.1038/srep01119

[2] Li, Y., Zhang, Q., Zhang, J., Jin, L., Zhao, X. and Xu, T. (2015) A Top-Down Approach for Fabricating Free-Standing Bio-Carbon Supercapacitor Electrodes with a Hierarchical Structure. Scientific Report, 5, Article ID: 14155. https://doi.org/10.1038/srep14155

[3] Zhou, F., Sun, W., Ricardo, K.B., Wang, D., Shen, J., Yin, P., et al. (2016) Programmably Shaped Carbon Nanostructure from Shape-Conserving Carbonization of DNA. ACS Nano, 10, 3069-3077. https://doi.org/10.1021/acsnano.5b05159

[4] Ding, W., Li. L., Xiong, K., Wang, Y., Li. W., Nie, Y., et al. (2015) Shape Fixing via Salt Recrystallization: A Morphology-Controlled Approach to Convert Nanostructured Polymer to Carbon Nanomaterial as a Highly Active Catalyst for Oxygen Reduction Reaction. Journal of the American Chemistry Society, 137, 5414-5420. https://doi.org/10.1021/jacs.5b00292

[5] Kaitsuka, Y., Hayashi, N., Shimokawa, T., Togawa, E. and Goto, H. (2016) Synthesis of Polyaniline (PANI) in Nano-Reaction Field of Cellulose Nanofiber (CNF), and Carbonization. Polymers, 8, 40. https://doi.org/10.3390/polym8020040

[6] Minas, C., Carnelli, D., Tervoort, E. and Studart, A.R. (2016) Printing of Emulsions and Foam into Hierarchical Porous Ceramics. Advanced Materials.

https://doi.org/10.1002/adma.201603390

[7] Malik, H.H., Darwood, A.R.J., Shaunak, S., Kulatilake, S., El-Hilly, A.A., Mulki, O., et al. (2015) Three-Dimensional Printing in Surgery: A Review of Current Surgical Applications. Journal of Surgical Research, 199, 512-522. https://doi.org/10.1016/j.jss.2015.06.051

[8] AlAli, A.B., Griffin, M.F. and Butler, P.E. (2015) Three-Dimensional Printing Surgical Applications. Eplasty, 15, 352-367.

[9] Gatenholm, P. (2016) Cellulose Nanofibrillar Bioink for 3d Bioprinting for Cell Culturing, Tissue Engineering and Regenerative Medicine Applications. WO Patent No. 100856

[10] Conner, B.P., Manogharan, G.P., Martof, A.N., Rodomsky, L.M., Rodomsky, C.M., Jordan, D.C., et al. (2014) Making Sense of 3-D Printing: Creating a Map of Additive Manufacturing Products and Services. Additive Manufacturing, 1, 6476. https://doi.org/10.1016/j.addma.2014.08.005

[11] Kieffer, M., Fuller, M.P. and Jelling, A.J. (1998) Explaining Curd and Spear Geometry in Broccoli, Cauliflower and "Romanesco": Quantitative Variation in Activity of Primary Meristems. Planta, 206, 34-43. https://doi.org/10.1007/s004250050371

[12] Swinton, J., Ochu, E. and the MSI Turing's Sunflower Consortium(2016) Novel Fibonacci and Non-Fibonacci Structure in the Sunflower: Results of a Citizen Science Experiment. Royal Society Open Science, 3, Article ID: 160091. 
https://doi.org/10.1098/rsos.160091

[13] Rong, C., Ji, A., Gao, L. and Cao, Ze. (2009) Stressed Triangular Tessellation and Fibonacci Parastichous Spirals on $\mathrm{Ag}$ Core $/ \mathrm{SiO}_{2}$ Shell Microstructures. Advanced Materials, 21, 4652-4657. https://doi.org/10.1002/adma.200901061

Submit or recommend next manuscript to SCIRP and we will provide best service for you:

Accepting pre-submission inquiries through Email, Facebook, LinkedIn, Twitter, etc. A wide selection of journals (inclusive of 9 subjects, more than 200 journals)

Providing 24-hour high-quality service

User-friendly online submission system

Fair and swift peer-review system

Efficient typesetting and proofreading procedure

Display of the result of downloads and visits, as well as the number of cited articles

Maximum dissemination of your research work

Submit your manuscript at: http://papersubmission.scirp.org/

Or contact soft@scirp.org 